\title{
LA DESUSTANCIALIZACIÓN DE LO SAGRADO Y EL HOMBRE DE BUEN CARÁCTER*
}

\author{
Rubén L. Vasconi \\ UNR
}

\section{Introducción.}

Asistimos en el mundo contemporáneo a un llamativo fenómeno: el renovado interés por lo religioso, el misterio, lo místico e irracional.

El fenómeno revela, por un lado, el fracaso del iluminismo positivista en su intento de crear una civilización fundada exclusivamente en la ciencia y la razón. Freud había afirmado, al final de El porvenir de una ilusión, "nuestro dios logos habla en voz baja pero termina por hacerse oír". La frase enunciaba el programa de una humanidad secular. Pero este "dios logos", hablando en voz tan baja, ha terminado por ser desoído en medio de la algarabía de las sectas, cultos esotéricos, orientalismos, "ufólogos" cuya espera de los extraterrestres corre pareja con el interés despertado por los ángeles, todo ello al lado de las grandes religiones tradicionales y los cultos populares, multiplicidad que ha configurado lo que se ha dado en llamar, con toda propiedad, un "supermercado de lo sagrado" ${ }^{\prime \prime}$. Simultáneamente se observa en las religiones tradicionales un progresivo "ablandamiento" de las doctrinas y la disciplina que hace lugar cada vez más a lo histórico, las costumbres de las comunidades, la piedad popular, en síntesis, a la multiplicidad de las "opiniones".

Como todo fenómeno social es susceptible de ser interpretado desde las ciencias sociales. Pero dado que nuestra especialidad es la Filosofía lo enfocaremos ahora desde nuestra perspectiva. El fenómeno revela ante todo la pérdida de la fe iluminista en la razón como facultad capaz de organizar y dar sentido a la vida humana. La fuerza de lo irracional que venía operando desde el existencialismo se patentiza ahora en la forma de un verdadero y por momentos "salvaje" retorno de lo reprimido.

\footnotetext{
"Comunicación presentada en las "III Jornadas de Comunicaciones de Investigación en Filosofía", Universidad Nacional del Litoral, Santa Fe, agosto de 2001. Tomamos la expresión "hombre de buen carácter" de Vattimo, J., Más allá del sujeto (Nietzsche, Heidegger y la Hermenéutica), Paidos, Barcelona 1989. p.23, quien la remite a Nietzsche.

${ }^{1}$ Lipovestky, G., La era del vacio, Anagrama, Barcelona, 1987, p.118.
} 
Pero además, pensamos que esta colorida y dispersa multiplicidad de fenómenos se sustenta en una nueva idea del ser y la verdad. Por tanto, el trasfondo de estos fenómenos observables y que constituye su condición de posibilidad es el giro que desde la fenomenología al pensamiento posmoderno se ha producido en el ámbito ontológico y en la concepción del conocimiento. A la nueva idea del ser como "acontecimiento" y a la idea hermenéutica de la verdad va a corresponder una concepción "desustancializada" de lo sagrado, manifestada en la multiplicidad de los fenómenos presentes y en el ablandamiento de las religiones tradicionales.

Y dado, por último, que el hombre configura su existencia en relación con lo que en su mundo le aparece como sagrado, surgirá una nueva figura humana ante esta sacralidad desustancializada. Podemos llamar a este nuevo tipo humano usando el vocabulario posmoderno, el "sujeto débil"2 o el "hombre de buen carácter".

Durante el desarrollo pondremos entonces en relación el fenómeno de la religiosidad contemporánea con las nuevas ideas de ser, conocimiento y verdad que lo sustenta. Paralelamente iremos mostrando los cambios que se operan en la figura del hombre acompañando a esta desustancialización de lo sagrado.

\section{I - Ser y verdad en la tradición occidental. La sustancialidad de lo sagrado}

La tarea de la Filosofía ha sido pensada desde los griegos como aquella reflexión que conduce de lo aparente a lo real. La alegoría platónica de la salida de la caverna expresaba con toda claridad esta idea.

Teníamos, como lo dado inmediatamente, las apariencias, múltiples, efímeras, contradictorias, cambiantes. Más allá estaba la verdadera realidad, sustancial y perdurable. Ya Parménides había establecido nítidamente los caracteres de esta "verdadera realidad": lo que es, es eterno, inmutable, permanece idéntico a sí mismo, tiene en sí su realidad, independiente y autosuficiente, perfecto. Por eso puede ser causa y principio.

Estos caracteres ontológicos sirvieron para pensar lo divino. Desde el Bien de Platón y el Acto Puro de Aristóteles, este modelo continúa en la Teología Cristiana y como algo evidente de suyo perdura hasta nuestros días. Dios, lo

\footnotetext{
${ }^{2}$ Vattimo, G., Op.cit.pp. 20 y 36.
} 
Sagrado, es el Ser Supremo, Verdadera Realidad. Lo demás, sólo es en la medida en que participa, refleja o es un efecto de este Ser Divino, Realidad Suprema.

Desarrollemos un poco más esta idea de lo Divino. Lo llamaremos el Dios Mayestático. Verdadera Realidad, Ipsum Esse, Señor, Principio y Rey del universo. Concentra en sí todo el poder y el saber. Infinito, omnipotente, nada escapa a su dominio. Todos estos caracteres hacen de Él un Ser Perfecto.

Esta idea de Dios representará el modelo sobre el cual el hombre habrá de modelar su existencia. Lo más perfecto será lo que más se aproxime al arquetipo divino. Los ideales supremos serán los de la grandeza, la sabiduría y el poder. Podríamos considerar como sus imágenes tradicionales al Papa y al Emperador, figuras que estaban reunidas en el Rey Filósofo de La República de Platón.

Recordemos que a esta idea de ser, realidad que en sí misma es lo que es, corresponde una idea de verdad. La verdad, es adecuación del espíritu humano a la realidad. Esta verdad, en el sentido fuerte, es el patrimonio del sabio que habiendo salido de la caverna puede reflejar lo que verdaderamente es.

El Rey Filósofo, encarnación de la verdad, ejerce legítimamente el poder ya que sabiendo qué es lo real, lo verdadero, bueno y justo, no necesita consultar a nadie para tomar sus decisiones. Los que no escuchan las palabras del sabio, o son idiotas que no lo comprenden o son perversos que, aunque sepan que la verdad está en la boca del filósofo prefieren seguir la invitación de sus pasiones. En tanto idiotas o perversos no merecen ser escuchados.

\section{II - La aligeración del ser y la verdad. La desustancialización de lo sagrado}

Al reiterar los posmodernos el anuncio de Nietzsche según el cual "Dios ha muerto", lo que quieren decir es que no hay tal "verdadera realidad". ¿Qué nos queda entonces? La multiplicidad de las apariencias, los fenómenos efímeros y fragmentarios que no pueden reducirse a la unidad. Se lleva así al extremo esa aligeración del ser que se había iniciado con la fenomenología husserliana y continuaba su desarrollo con Heidegger y el existencialismo.

Recordemos algunos pasos del pensamiento de Husserl. Éste, tratando de hacer de la Filosofía una ciencia estricta y sin supuestos, había propuesto como consigna fundamental del pensar el "ir a las cosas mismas". Esto inmediatamente dado en la intuición debe describirse tal como se da pero también dentro de los límites en que se da. Ponemos entonces entre paréntesis (reducción tras- 
cendental) la realidad en sentido estricto y reducimos el mundo a la multiplicidad de fenómenos puros, correlato intencional de los actos puros ante los cuales se configuran como presencias significativas. El "ser real" como el "ser aparente" o "imaginario" no son más que características del fenómeno en cuanto a su modo de darse.

Heidegger continúa esta reflexión en el mismo plano de la reducción trascendental. Ni el "ser ahí" ni el "mundo" son algo "real" sino el resultado del entrecruzamiento de una trama de relaciones.

Esta visión de un mundo móvil, insustancial, constituido por el sucederse vertiginoso de fenómenos efímeros continúa, más o menos acentuado, en todos aquellos pensadores que pondríamos bajo el rótulo de fenomenología existencial.

Ahora bien, este mundo efímero y evanescente, era vivido por estos autores en la forma de la angustia ante la falta de un fundamento sólido. Así decía, por ejemplo, Gabriel Marcel: "es necesario que haya, o sería necesario que hubiese ser, es decir, algo que resista. Que no podamos decir: todo es vanidad"3. También en el "cuarteto" (das Geviert) heideggeriano, nos encontramos con que vivimos en la tierra, con los hombres, bajo el cielo pero, esperando los dioses ${ }^{4}$.

Si lo expresásemos en un lenguaje venido del psicoanálisis, podríamos decir que todo este pensamiento estaba habitado por la nostalgia del Padre Protector. Pero este Padre Protector era también un Padre Opresor. La muerte de Dios, la ausencia de todo fundamento sólido es ahora vivido de otra manera: como la experiencia de una libertad gozosa, la conciencia de no ser oprimidos por nada real.

En la fuente de este nuevo modo de pensar se encuentra un hecho histórico-social al que los posmodernos asignan un valor capital: el explosivo desarrollo de los medios de comunicación. A diferencia del hombre del pasado que vivía encerrado en un pequeño mundo, gracias a los mass-media (periódicos, revistas, radio, cine, televisión) y las ciencias sociales, el hombre contemporáneo, en cambio, vive un brusco ensanchamiento de su campo de experiencia, enfrentado a múltiples mundos, estilos de vida, propuestas de todo tipo imposibles de ser

\footnotetext{
${ }^{3}$ Marcel, G. Position et approches concrètes du mystère ontologique. Nauwelaerts - Vrin, Louvain París, 1949, p. 51

${ }^{+}$Heidegger, M. Bauen Wohnen, Denken, en Vorträge und Aufsätse, Pfullingen, Neske, 1957, pp. 145-162.
} 
reducidos a la unidad. Este ensanchamiento de nuestra experiencia engendra un espacio abierto a nuestra libertad.

\section{III - EI ser débil y la verdad hermenéutica. La insustancialidad de lo sagra- do}

\section{a) Las múltiples figuras de lo sagrado}

Los posmodernos han tratado de elaborar una ontología que corresponda a nuestra experiencia actual del mundo.

El "ser fuerte" y la "verdad fuerte" constituían el sustento de un "sujeto fuerte", capaz de afrontar las circunstancias en épocas de vida violenta. Pero la organización tecnoburocrática de la sociedad y la producción han hecho a la vida más segura, de manera tal que hoy podemos prescindir de ese reaseguro de carácter "mágico". La creencia en la metafísica - es decir: la creencia en que hay "algo real" - no se rechaza en nombre de una verdad más verdadera ni de una realidad más real sino que su rechazo tiene el carácter de una despedida ( $A b s-$ chied). No se trata de que el ser y la verdad fuertes constituyan una tesis falsa, simplemente no las necesitamos. Esta despedida de la metafísica es un "acontecimiento" que el filósofo constata y relata.

Despedida la metafísica no nos queda nada real. El ser se manifiesta y ocurre en la forma de múltiples y cambiantes horizontes de sentido sobre cuya base comprendemos los entes. Los conceptos que nos permiten pensar este ser "aligerado" e insustancial, ya no son: identidad consigo mismo, permanencia, eternidad, sino más bien, vida, juego, mortalidad, historia. Este ya no es un ser real (sólido, sustancial, perdurable) sino débil y declinante ${ }^{5}$, un ser que su cede.

Estos mismos caracteres se trasladan a la verdad. El conocimiento, en lugar de ser comprendido como la captación, desde fuera, de una realidad y expresado en una proposición que describe fielmente esta realidad, "es evento, respuesta a los mensajes que provienen de una tradición, interpretación de estos mensajes y acaecimiento de un mensaje nuevo transmitido a otros interlocutores"6.

Además, en lugar de una ciencia unificada que se cierra en un saber absoluto (Hegel) aparecen en el mundo presente múltiples saberes, cada uno con su propia jerga (dialecto) o como juegos de lenguaje incomunicables entre sí. De-

\footnotetext{
${ }^{5}$ Vattimo,G., Rovatti, P.A. (eds), El pensamiento débil .Cátedra, Madrid 1988, p..34.

${ }^{6}$ Vattimo.G., Ética de la interpretación. Paidos, Bs. As., 1992, p.67.
} 
ntro de estos saberes deben ser hoy contados el pensar narrativo (mito) o los lenguajes de las subculturas. La multiplicidad de criterios de verdad da lugar a un irracionalismo moderado o una racionalidad moderada ${ }^{7}$ que priva de toda justificación a los violentos y fanáticos.

Llegamos así a la dispersión de múltiples y diferentes mundos, verdades, formas de belleza y, naturalmente, figuras de lo sagrado. Desde esta ontología se revela ante nosotros el colorido espectáculo del supermercado de lo sagrado y, en conexión con esta multiplicidad, la variedad de ritos, devociones y prácticas en que se van configurando distintos tipos humanos ante estas variedades de lo sagrado.

Los "matices" y "escorzos" de que hablaba la fenomelogía husserliana y que todavía algunos podían interpretar como manifestaciones parciales de algo real, son ahora, todo lo que hay. Los múltiples rostros de lo sagrado no remiten a un trasfondo perdurable, no son los apareceres finitos de La Divinidad (en singular). La multiplicidad de los fenómenos y los saberes no pueden reducirse a la unidad.

Desde esta ontología, la variada oferta del supermercado de lo sagrado no puede ser trascendida hacia una realidad sustancial que estuviese más allá. El politeísmo es la última palabra. Paralelamente, la concepción hermenéutica de la verdad genera un necesario ablandamiento de las doctrinas tradicionales que ya no pueden ser pensadas como la verdad sin más (espejo de la realidad) sino como una interpretación contingente, histórica y susceptible de permanentes reinterpretaciones, de un mensaje. Con la muerte de Dios se han extinguido las mayúsculas: la Realidad, la Unidad y la Verdad.

\section{b) El Cristianismo del Dios débil}

Otra forma en que esta desustancialización posmoderna de lo sagrado se nos hace presente es la que encontramos en la propuesta de un cristianismo del Dios Débil que ha desarrollado Gianni Vattimo en algunos de sus trabajos ${ }^{8}$.

Este autor comienza destacando la existencia de una profunda convergencia entre el pensamiento posmoderno y la predicación cristiana (se entiende que posmodernamente interpretada). La circunstancia histórica de que esta predicación se hubiese desarrollado como doctrina dentro de los cuadros de la filoso-

\footnotetext{
${ }^{7}$ Vattimo, G., La sociedad transparente Paidos, Barcelona, 1990, p 121.

${ }^{8}$ Vattimo, G., Más allá de la interpetación, Paidos, Barcelona, 1995; Creer que se cree, Paidos, Barcelona, 1996; "Entrevista a G. Vattimo". Gritex, 5-6, Rosario, 1993.
} 
fía grecorromana y de la idea parmenídea de ser, ha dejado encubierto cuál era el Dios del que Jesús hablaba. En su lugar aparece el Dios violento de la Metafísica y de la Religión Natural, Aquél que se manifiesta en las potencias destructivas de la naturaleza - la tempestad y el rayo - y que desde su absoluta trascendencia niega todo aquello que para el hombre es razonable y bueno. Es también el Dios Veterotestamentario, el Ganz Andere retomado por la teología dialéctica que se inspira en Tertuliano y Kierkegaard.

El Dios que predica Jesús no es el Amo y Señor sino el Abba, cercano y amistoso. No es el Dios Todopoderoso y distante sino el Dios kenótico (Pablo, Filip. 2, 5-8) que se ha vaciado de su "maiestas". La Encarnación es un anonadamiento del Dios Suprema Realidad.

Podríamos, tal vez, ilustrar esta idea apelando a la Teología Occamista que hace hincapié en la libertad divina. ${ }^{9}$ Dios, decidido a encarnarse, pudo haber tomado cualquier figura. Pudo petrificarse y aparecer como una roca sagrada. $\mathrm{O}$ encarnarse en un asno. $\mathrm{O}$ tal vez, mostrarse como Emperador de Roma y entonces, presumiblemente, apoyado por sus legiones su predicación hubiese tenido más éxito ( ¿es el éxito un valor cristiano?). Pero prefirió tomar la figura de un ser débil, un trabajador manual de los confines del Imperio. Si pensamos que asumió la imagen que mejor lo hacía conocer a los hombres ("quien a Mí ve, ve al Padre"), el ser de Dios no sería el Ens Realissimum, distante y todopoderoso sino cercano, no aterrador sino amigable, un Dios Débil que se complace en la amistad con los hombres. La predicación cristiana estuvo en sus orígenes dirigida contra el Dios de la Metafísica, el Dios Veterotestamentario, el Dios Mayestático de la Religión Natural.

También la verdad se debilita. La verdad nace de una hermenéutica que continúa, es la obra, no sólo de un grupo de expertos sino de una comunidad popular interpretante. La esencia del mensaje cristiano es la predicación de la caridad. Éste es el criterio que perdura. Por lo tanto, toda interpretación será buena y verdadera en la medida en que naciendo de la caridad, la promueva.

Desde luego que si el hombre se configura desde lo que en su mundo le aparece como Sagrado, el nuevo hombre no será ya el sujeto fuerte y rígido de la metafísica. Será en cambio, el hombre de buen carácter que, imbuido de la caridad estará siempre abierto al otro, al cambio y a la diferencia.

\footnotetext{
${ }^{9}$ Citado en Eliade, M. , Tratado de historias de las religiones, Cristiandad, Madrid, 1974, T. I, p. 54.
} 


\section{IV- Conclusión}

Con la desaparición de la "verdadera realidad" también se extinguen los "valores enfáticos" (Justicia, Verdad, Historia, Humanidad), todos aquéllos que se escribían con mayúscula y por los cuales - se suponía - debíamos estar dispuestos a todo tipo de sacrificios, incluido el de nuestras vidas y la de los otros. No quedan más que los pequeños valores: las verdades locales, el terruño, la tradición familiar, no la Humanidad sino algunos vecinos. Carente de un sustento metafísico, el héroe hegeliano, con toda su grandeza, habrá desaparecido.

Suprimida toda esta grandeza de lo Universal, parece, entonces, que sólo nos queda la frivolidad de la vida cotidiana, los pequeños placeres y problemas que nacen de cultivar nuestra diferencia, la liviandad de una existencia mezquina que rehuye todo compromiso.

Pero, de entre las ruinas de lo que ha muerto, ¿no estaría naciendo una nueva esperanza?

El héroe hegeliano portador del Espíritu Universal, caminaba sobre los cadáveres de los inocentes ${ }^{10}$. Preocupado por la Humanidad era sordo ante el dolor de su vecino. Así, lo Universal, lo Uno, en resumen, lo Abstracto, permitían encubrir lo único real, el frágil existente de carne y hueso.

El gran engaño ha sido el culto a la grandeza. Alejandro Magno, Carlo Magno, y todos los otros "Magnos" cuyas estatuas adornan nuestras plazas han traído al mundo más dolor que alegría. Lo que ocurre es que sus víctimas, sacrificadas en el altar de la grandeza, no han podido dejar testimonio de su sufrimiento.

Verdaderamente "magno" ha sido el olvidado inventor de la rueda, un hombre inteligente pero también perezoso y compasivo que estuvo buscando algún medio para librarse y librar a sus amigos de tener que cargar bultos pesados. Un homenaje semejante merecería la inventora del queso, seguramente una mujer, una gordita golosa que gustaba de la buena mesa, una persona feliz que no vivía como el héroe hegeliano con los dientes apretados y que, buscando su placer, ha regalado a la humanidad uno de los bienes más preciados.

\footnotetext{
${ }^{10}$ Hegel, G.W.F, Lecciones sobre la Filosofia de la Historia Universal. Alianza, Madrid, 1982, pp.79 -100 .
} 
La marcha ascendente de la humanidad ha sido el resultado del amor inteligente o de la inteligencia movida por el amor, no del uso de la espada ${ }^{11}$. Y el amor se dirige a lo concreto, lo inmediato, lo cercano.

Tal vez hoy sea imprescindible olvidar los ideales de grandeza (grandes ciudades, grandes edificios, gran producción). Ya todos sabemos que son totalmente disfuncionales, contaminantes, malsanos, peligrosos.

La propuesta será generar una civilización "minimalista", exaltando el valor de lo pequeño, lo débil, lo apenas audible y visible, aquello que sólo se descubre si aguzamos la vista o acercamos el oído, a diferencia de ese espectáculo ensordecedor que nos aplasta y nos abruma.

El nuevo hombre, devoto del Dios Débil, será pequeño y silencioso pero con un agudo sentido de los finos y casi imperceptibles matices de lo real. Frente a la fuerte brutalidad del héroe de la grandeza encontraremos la rica delicadeza de la debilidad.

\title{
Resumen
}

La presente comunicación supone que el hombre configura su ser, entre otras cosas, por la figura de lo Sagrado que le aparece en su mundo. Recorre entonces los cambios que se han producido desde una idea de lo Sagrado como suprema realidad y del modo humano que le corresponde hasta la figura de un Dios Débil. En relación con este modo de lo Sagrado, vemos aparecer un nuevo ideal humano, caracterizado por la exaltación de los valores "minimalistas" de la pequeñez y la debilidad.

\begin{abstract}
The present communication supposes that the man forms his being, among other things, from the figure of the Sacred that appears in his world. Therefore, he crosses the changes that have taken place from an idea of the Sacred as supreme reality, and the human way that corresponds to the figure of a Weak God. In relation to this way of the Sacred, we see a new ideal human being characterized by the exaltation of "minimalist" values of the smallness and the weakness.
\end{abstract}

\footnotetext{
${ }^{11}$ Montagu, A., La revolución del hombre Paidos, Bs. As. 1967, pp. 214/5.
} 